\title{
PRURIGO NODULARIS
}

\section{(A Case Report)}

\author{
Sqn Ldr S GROVER ${ }^{*}$, Wg Cdr H SUBRAMANYA ${ }^{+}$
}

MJAFI 1996; 52 ; 258-259

KEY WORDS : Pruritus; Prurigo nodularis.

A multitude of cutaneous and systemic disorders manifest as pruritus. A papular or nodular reaction pattern to pruritus is termed as prurigo, characterized by chronic, intensely itchy nodules. Though the acute forms of prurigo are more common and occur as a result of arthropod bites, the chronic form is a relatively rare condition. Prurigo nodularis is believed to be idiopathic although a variety of factors have been postulated as aetiological factors [1].

A case of prurigo nodularis is reported here owing to its rarity in clinical practice and characteristic histopathological features.

\section{Case Report}

A 54-year-old female, resident of Maharashtra, reported with multiple raised and itchy lesions all over the trunk, both upper and lower limbs of 17 years duration. At the onset, a few bullous lesions had appcared over her left Icg which regressed to form itchy nodules. Over the next ten years she developed intensely itchy nodules over face, scalp, both upper limbs, both lower limbs and trunk. The older lesions regressed very slowly but never disappeared entirely. However, for the last 7 years there was no increase in size or number of lesions. There werc no constitutional or systemic symptoms. She denied history of drug intake prior to onset of symptoms. There was no history of atopy. She had been given low dose systemic corticosteroids and Avil off and on, by a medical practitioner. None of her children had similar disorder and were apparently healthy.

General examination revealed an obese individual (height $151 \mathrm{~cm}$, weight $64 \mathrm{~kg}$ ) with pallor. There was no lymphadenopathy. Systemic examination did not reveal any abnormalities. Dermatological examination revealed multiple, bilaterally symmetrical hyperpigmented papules and nodules over the face, front of chest, abdomen, back of trunk, both upper limbs, gluteal region and both lower limbs (Fig I). Excoriation was present. Older lesions were flat and associated with post-inflammatory hyperpigmentation. There was no scaling, vesication or oozing. Mucosae, hair, nails and genitalia were normal.

Investigations revealed anaenia. Total and differential white cell count, serum crealinine, stools for ova/cyst, blood urea, scrum electrolytes and chest radiography were normal. Peripheral blood smear revealed a microcytic hypochromic picture. Skin biopsy was performed and stained with H\&E stain. 'This showed a classical histopathological pattern with hyperkcratosis, acanthosis, papillomatosis and irregular downward proliferation of the epidermis. There was a non-specific infiltrate of chronic inflammatory cells in the dermis. Serial sectioning failed to reveal any colloid bodies, basal cell degeneration or pseudo-epitheliomatous hyperplasia (Fig 2).

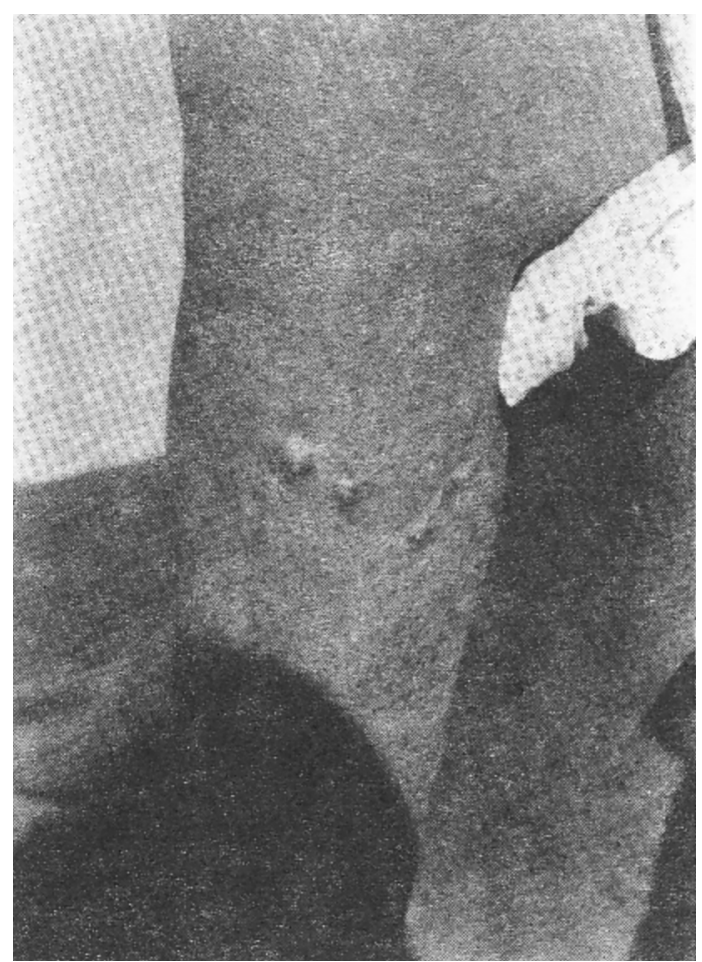

Fig. 1: Clinical photograph of the right leg, showing multiple, excoriated, hyperpigmented nodules.

\footnotetext{
"Graded Specialist (Derm \& Ven), Command Hospital (Air Force) Bangalore - 560007; ${ }^{+}$Classified Specialist (Pathology), Air Force Central Medical Establishment, New Delhi - 100010
} 


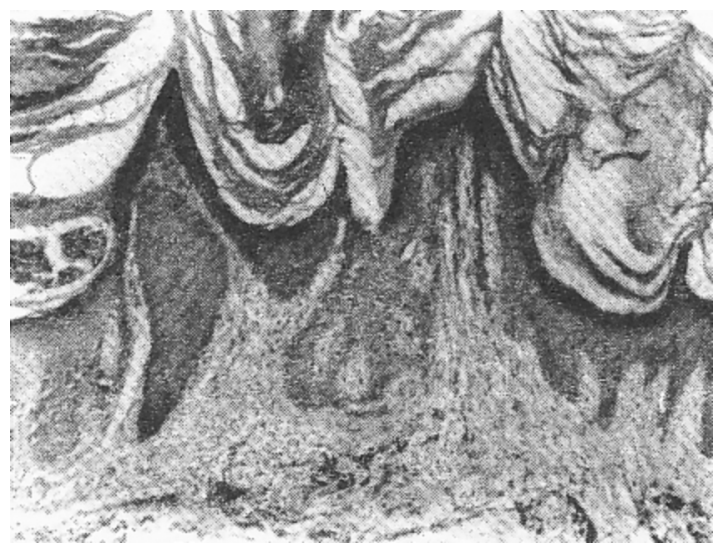

Fig. 2: Skin biopsy showing hyperkeratosis, papillomatosis and irregular downward proliferation of the epidermis. Dermis shows non-specific chronic innammatory infilterate. (H\& E, $40 X)$

Based on the clinical and histopathological evidence, she was diagnosed as a case of prurigo nodulatis and treated with topical steroids and systemic antihistaminics. She was followed up for 8 weeks during which pruritus lessened and the lesions regressed marginally. They, however, did not disappear entirely.

\section{Discussion}

Prurigo nodularis may present at all ages but mainly occurs in middle aged elderly individuals. The exact aetiology is unknown, though emotional stress can be a contributory factor. Close to $80 \mathrm{per}$ cent of these patients are atopic though there may be no eczematous lesions. In the remaining 20 per cent the condition is said to start after an insect bite [2]. The pruritic nodules are characteristically distributed over the distal limbs, upper trunk and gluteal region and are worse over the extensor surfaces, though any part of the body can be affected. The patients are tormented by crises of intensely severe pruritis occuring daily and lasting a few minutes to a few hours. Our case had papular and nodular lesions all over her body with a special prediliction for extensor surfaces. As there was no history of atopy, bullous lesions over the leg could have resulted from unrecognized insect bites.

A multitude of underlying diseases, metabolic and haematological disorders, can occur in association with prurigo nodularis $[1,3,4]$. Our patient and anaemia. Since she was from a lower socioeconomic strata and her systemic examination was normal, anaemia was thought to be nutritional in aetiology.

Neurohistopathological studies have revealed thickened dermal nerve fibres [5]. Immunocytochemical staining for calcitonin gene related peptide (CGRP) and substance $P$ immuno-reactivity in the cutaneous nerve fibre bundles is positive. These neuropeptides play an important role in causing itching [6]. However, these neurohistological findings require special stains for delineation and even then are not prominent and less constant $[1,7]$. In the H\&E stain used by us this feature was not demonstrated.

The treatment of this rare disorder is mainly symptomatic. While pruritus is relieved by antihistaminics, stress is alleviated by tricyclic antidepressants. Other effective modalities of treatment are cryotherapy [8], thalidomide [9], topical or intralesional steroids, UVB phototherapy, psoralen photochemotherapy and benexoprofen [2]. Despite treatment new nodules may develop. The existing nodules may remain pruritic indefinitely or regress spontaneously leaving scars.

\section{REFERENCES}

1. Rowland-Payne CME, Wilkinson JD, McKee PH, et al. Nodular prurigo - a clinicopathological study of 46 patients. Br J Dermatol 1985; 113: 431-9.

2. Kundu A, Wade $A \wedge H$, llchysliyn A. Prurigo nodularis in an HIV pasitive man (letter to editor). Genitourin Med 1995; 71: 129-30.

3. Jorizzo JL, Gatti S, Smith EB. Prurigo: a clinical review. J Am Acad Dermatol 1981; 4: 723-8.

4. McKenzie AW, Stubbing DG, Elvy BL. Prurigo nodularis and gluten enteropathy. Br J Dermatol 1976; 95: 89-92.

5. Cowon MA. Neurohistological changes in prurigo nodularis. Arch Dermatol 1964; 89: 754-8.

6. Vaalasti A, Suomalainen H. Calcitonin gene related peptide immunoreactivity in prurigo nodularis : A comparative study with neurodermatitic circumscripta. Br J Dermatol 1989; 120; 619-23.

7. Lever WF, Schaumberg-Lever G. Histopathology of the skin. 7th ed. Philadelphia: Lippincott, 1990: 155-6.

8. Waldinger TP. Wong RC, Cryotherapy improves prurigo nodularis. Arch Dermatol 1984; 120: 1598-600.

9. Vander Broek H. Treatment of prurigo nodularis with thalidomide. Arch Dermatol 1990; 116: 571-2. 